\title{
Is teaching ready for the part-timer?
}

\author{
Richard Pearson
}

Britain's schools are struggling to come to terms with the challenge of a changing society.

THE school system is the life blood of British science, and the 1990s promise to be a decade of dramatic change as the government's education reforms start to be implemented. Will the staff be there to cope with the mixture of increased institutional autonomy, tighter curricula framework and the need to respond to market forces?

There are more than 400,000 teachers employed in state schools in England and Wales, 95 per cent of whom work full time, and although the number has been falling in recent years there is growing concern about the shortages of teachers, particularly in science-based subjects.

One of the problems that cloud debate about the solutions to teacher shortages is the lack of reliable data. At the basic level, we do not even know how many people are employed in the education system: the published total of 429,000 refers to the number of full-time equivalents (FTEs), not individuals. In addition, there are a further 50,000 teachers (FTEs) in the independent (non-state) sector. More importantly there are also a further 395,000 qualified teachers not currently working in the profession.

The precise number of vacancies is also unknown and largely unquantifiable as posts may be withdrawn, or the number of hours for a particular subject in the timetable reduced if the school thinks vacancies cannot be filled - this is known as a 'suppressed' shortage. Alternatively, pupils may be taught by teachers who are not qualified or trained in the subject, a 'hidden' shortage. Nevertheless, the available data show a vacancy rate in secondary schools of 1.1 per cent in 1987, up from 0.78 per cent in 1982 . On a subject basis then, the highest vacancy rates are in computing and business and commercial studies, while the high levels in mathematics, physics and CDT (craft design technology) seemed to have eased for last year at least. By contrast, vacancy levels have been rising in languages and some other subjects. On a regional basis, Greater London suffers most at secondary level with a vacancy rate of around 3 per cent, but this conceals wide local variations from a suburban 0.4 per cent to an inner city area with a vacancy rate of 5.6 per cent.

The other side of the shortage picture is that of wastage, and the evidence here is of a relatively stable profession with losses from teaching averaging 5.5 per cent, the dominant destination being retirement and out of employment altogether. Only one in ten of the secondary teachers leaving went to jobs outside teaching, a loss rate of less than 1 per cent from the profession.

Recruits to fill these and other vacancies come from three main sources. In the 1970 s, entry to the profession was dominated by school-leavers going to teacher training college, supplemented by a cohort of graduates, some but by no means all undertaking postgraduate teaching courses. Together they accounted for nearly three out of four of those taking up teaching posts. Since that time, there have been major changes in basic teacher training, with the old teacher training colleges being absorbed by the polytechnics and colleges and the main qualification, now the Bachelor of Education, achieving degree status. For the past decade, entrants to teaching have had to undergo special training, although this requirement was initially waived in the case of shortage subjects such as mathematics, a policy which allowed a continuing inflow of untrained teachers into the profession. This may to some extent explain the comparatively low attainment level subsequently experienced in these subjects. Overall, the numbers completing initial teacher training fell from around 40,000 to under 15,000 in the decade to 1986 , a decline managed by the government in the light of reducing job opportunities for teachers. Not all of those trained went straight into teaching, the figure for the early 1980 s being under 60 per cent although it has since been rising to reach 65 per cent in 1986. Two thirds of these entrants were women, and 60 per cent were aged under 25 .

While the traditional entry cohort of young entrants has been falling fast, the number of re-entrants initially fell from 14,000 to 11,000 but has since remained broadly stable. As a result, their share of the annual intake has risen from 1 in 4 to 1 in 2 over the past decade. These reentrants are, as might be expected, predominantly women ( 90 per cent of the total) and clustered in the 30-45 age range. The third entry group are those from abroad or those without previous training and they have remained a small
(2-3 per cent) but increasing proportion.

What then of the future? The number of teachers needed depends particularly on the size of the school population, which is expected to continue to fall at secondary level for much of the next decade although the number of children at primary age will be rising. On current policies, the number of secondary teachers needed could decline by about 7,000 , an overall decline of about 10 per cent. Of equal importance, however, are the effects of changes in educational policy such as the planned core curriculum, which should in theory boost the demand for teachers in subjects such as mathematics, science and languages. The level of government expenditure for education is also critical and as yet unknown. While the impact on the numbers of teachers employed must be unknown at this stage, it seems more likely that they will fall rather than rise over the next decade.

There is a fine balance between the numbers leaving the profession and those joining it, with problems in certain subjects and localities. On the supply side, organizers of teacher training will be facing increasing competition for the shrinking supply of school leavers (see Nature 335, 100; 1988) and of graduates to enter postgraduate teacher training (see Nature $334,90 ; 1988)$. It has been estimated that next year 8.2 per cent of school leavers with two A-levels will have to enter teacher training (up from 6.2 per cent in 1984) while 1 in 10 graduates will have to do so, a figure that rises to 1 in 5 in the case of mathematics and computing graduates and 1 in 2 of those graduating in French. Given the growing demand for graduates elsewhere in the economy, a factor that may also increase wastage rates, these seem impossible targets unless the attractiveness of teaching as a career is significantly improved. A more hopeful strategy would be to increase the intake of mature entrants to teacher training and to boost the number of re-entrants from the pool of nearly 400,000 trained teachers who are not currently working. To do this, more opportunities will have to be made for part-timers.

Richard Pearson is at the Institute of Manpower Studies, Mantell Building, University of Sussex, Britghton BNI 9RF, UK. 